\title{
Special Issue: 11th International Symposium on Dynamic Problems of Mechanics - XI Diname
}

The International Symposium on Dynamic Problems of Mechanics - DINAME, is held every two years since 1986, organized under the responsibility of the Committee of Dynamics of the Brazilian Society of Engineering and Mechanical Sciences (ABCM). It is a well-established forum for discussion of dynamic problems of Mechanics and has traditionally had the participation of researchers from Brazil and various other countries. The eleventh edition of the symposium was held from February 28 to March 4, 2005 in Ouro Preto, Minas Gerais, Brazil, being locally organized by the School of Mechanical Engineering, Federal University of Uberl ândia and co-chaired by Drs. Domingos Rade and Valder Steffen Jr.

One hundred papers were presented in the Symposium, including eight invited lectures. Twenty-four papers were selected for the present special issue, after having been subjected to the standard peer-reviewing process adopted for the evaluation of regular papers submitted for publication in Shock and Vibration.

A special note of gratitude is addressed to all participants whose attendance and contributions helped to foster important discussions on issues associated with problems related to vibration and acoustics, modal analysis, controls, smart structures, rotordynamics, robotics, nonlinear dynamics and multibody systems.

Finally, the efforts of Prof. D. Inman, Editor-in-Chief of Shock and Vibration, in editing this special issue are greatly appreciated.

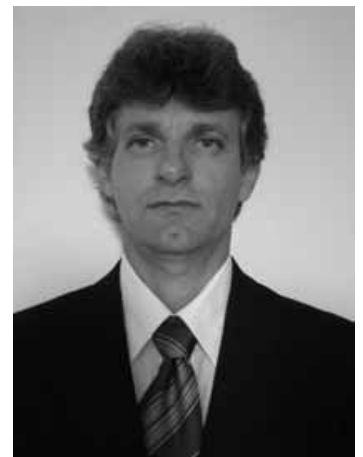

Prof. Domingos A. Rade Guest Editor

Federal University of Uberlândia School of Mechanical Engineering

Campus Santa Mônica 38400-902 Uberlândia - MG - Brazil

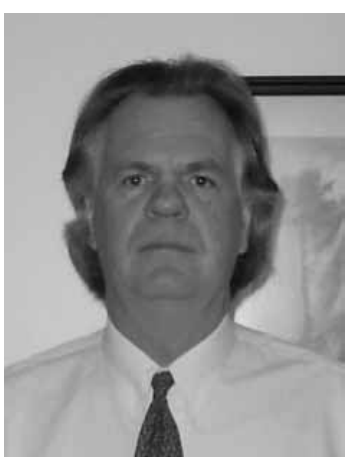

Prof. Valder Steffen, Jr Guest Editor

Federal University of Uberlândia School of Mechanical Engineering Campus Santa Mônica 38400-902 Uberlândia - MG - Brazil 

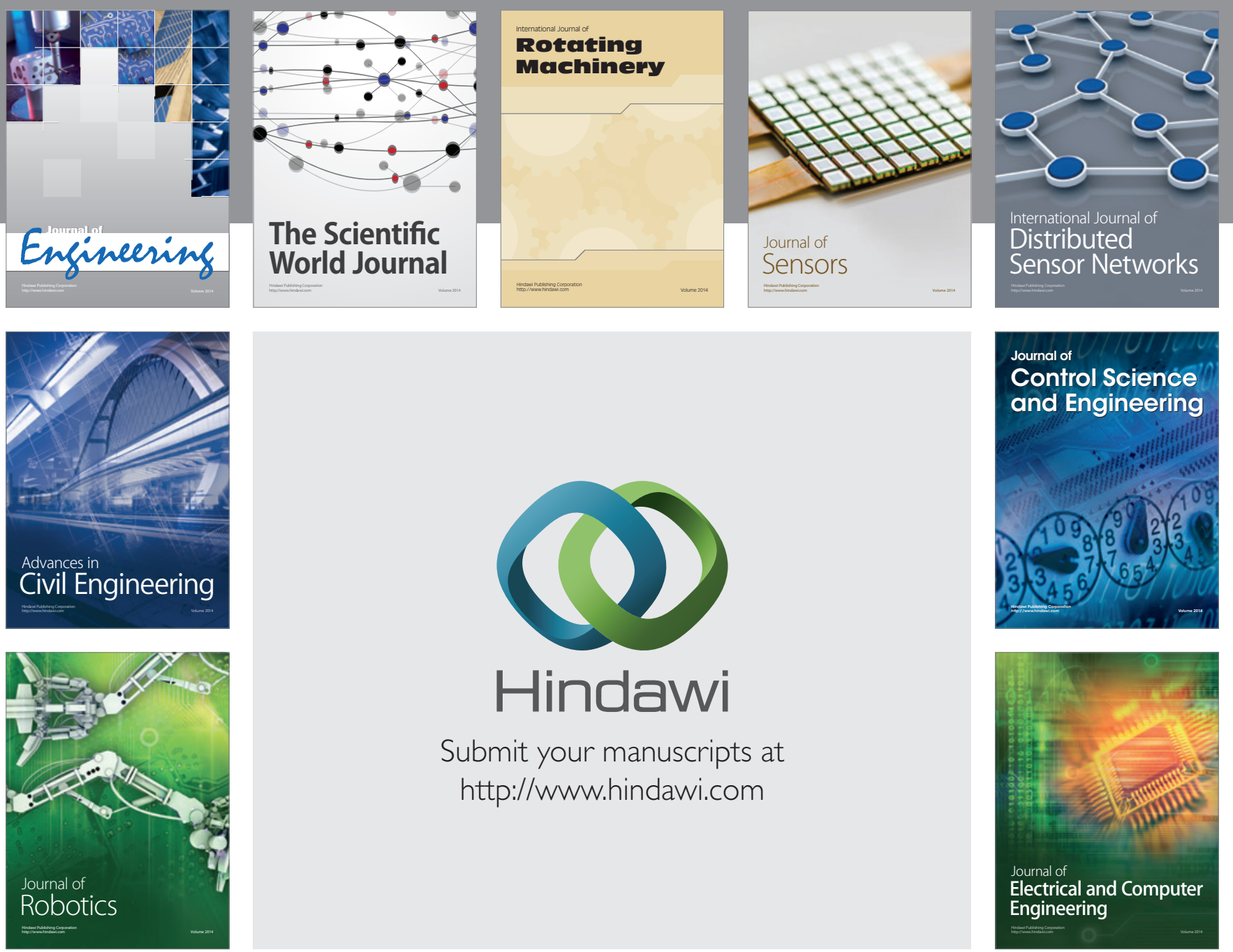

Submit your manuscripts at

http://www.hindawi.com
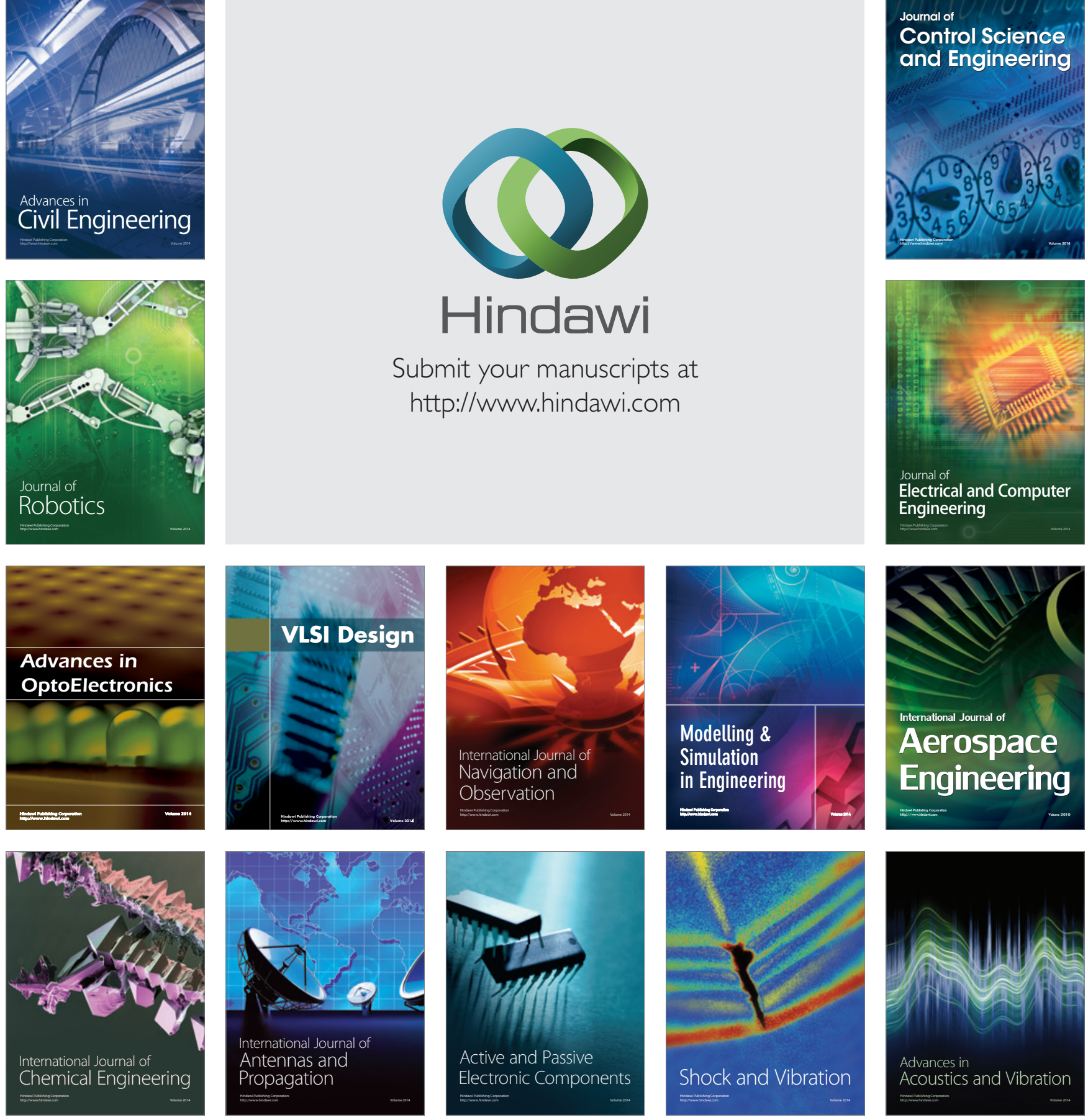